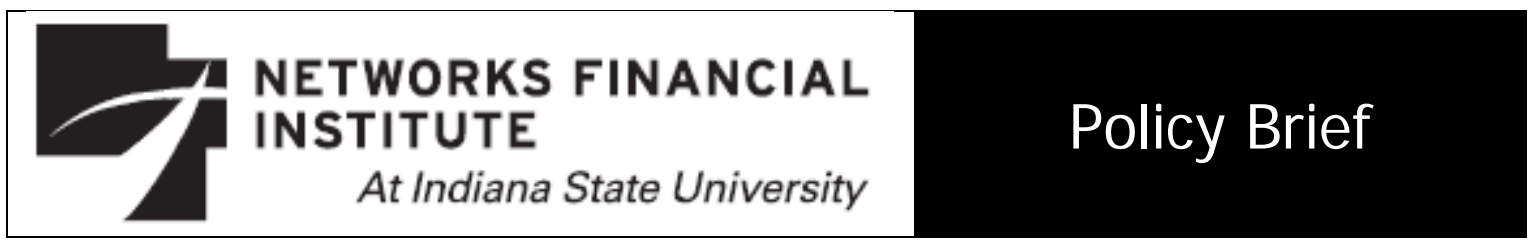

2013-PB-04

August 2013

\title{
Should Financial Regulators Engage in International Policy Coordination?
}

\section{David VanHoose}

Abstract: This policy brief examines issues associated with the design and implementation of regulatory policymaking in interconnected financial markets. The policy brief explains why international interdependence among nations' financial markets and regulations can provide an incentive for national financial supervisory agencies to contemplate coordinating their regulatory policies. It also assesses, in the context of a review of recent research on the part of banking and financial economists, ways in which interdependence among financial systems can create a potential for international regulatory policy conflicts. In addition, the policy brief evaluates whether such conflicts are insurmountable or might be somewhat mitigated at least somewhat via bargains among regulatory authorities.

About the Author: David VanHoose earned his Ph.D. at the University of North Carolina at Chapel Hill and is currently the Herman W. Lay Professor of Private Enterprise at the Hankamer School of Business at Baylor University and a Senior Fellow at Networks Financial Institute. His work has appeared in Oxford Economic Papers, the Journal of International Money and Finance, and the European Journal of Political Economy. VanHoose served as a Visiting Economist at the Board of Governors of the Federal Reserve System in 1988 and as a Visiting Scholar at the Federal Reserve Bank of Kansas City in 1989. He currently is a co-editor at Open Economies Review and serves on the editorial boards of the Journal of Economics and Business and the Atlantic Economic Journal. VanHoose is also the author of E-Commerce Economics, co-author (with Roger Leroy Miller) of Macroeconomics: Theories, Policies, and International Applications and Money, Banking and Financial Markets, and co-author (with J oseph P. Daniels) of International Monetary and Financial Economics and Global Economic Issues and Policies.

Keywords: international financial regulation, financial regulatory coordination. J EL classification: G2, G28, F3, F5

The views expressed are those of the individual author and do not necessarily reflect official positions of Networks Financial Institute. Please address questions regarding content to David VanHoose at David_VanHoose@baylor.edu. Any errors or omissions are the responsibility of the author.

$\mathrm{NFI}$ policy briefs and other publications are available on NFI's website http://indstate. edu/business/NFI/leadership/publications/ 


\section{Should Financial Regulators ENGAGE IN INTERNATIONAL POLICY COORDINATION?}

\section{Introduction}

An interesting feature of the activities conducted by national financial supervisory authorities from the 1980s through the early part of the current decade was the presumption that coordination of regulation was both desirable and feasible. Indeed, the Basel I, II, and III frameworks were predicated on this presumption.

Recently, however, national financial supervisors increasingly have struggled to coordinate their actions. As discussed by Blackstone (2013) and in The Economist (2013), efforts to establish uniform financial supervisory policies in Europe so far have failed. Meanwhile, the nature of national regulators' policy responses to European bank failures have been, as summarized by Steinhauser (2013), very diverse. Furthermore, as reported by Miller (2013), U.S. authorities have begun requiring foreign institutions to meet the same standards imposed on domestic institutions. Some U.S. supervisors have even contemplated rejecting the Basel III agreement [see Zibel (2012)] or unilaterally implementing an altered set of Basel capital rules whether or not other national supervisors concur [see Crittenden (2013)]. Crittenden and Enrich (2013) describe a global "regulatory rift."

Economists who have studied past efforts to coordinate national monetary, fiscal, and trade policies - or prior attempts by firms seeking to operate collusive cartels - surely are not surprised by these signs of actual and potential breakdowns in coordination of financial supervision. Widespread global interest in the idea of coordinating national economic policies developed among many economists and policymakers early in the 
1980s. Much initial research suggested substantial gains could be reaped. Follow-up work, however, cast light on a number of difficulties that policymakers would likely confront if they were to try to pursue coordination agreements. In the years since, real-world efforts to coordinate monetary, fiscal, and trade policies have been irregular and have yielded mixed results.

Among financial supervisory authorities, the recent sudden divergence of regulatory policies has come as something of a shock. Only within the past few years have very many banking and finance researchers raised questions about national supervisory authorities' long-held assumption that international coordination is always desirable. Furthermore, most of the recent studies of international financial regulatory policy coordination largely have been disconnected from the broader economics literature on policy coordination. This literature offers a number of lessons to those seeking to evaluate the pros and cons of harmonizing the policies of financial supervisors. Nevertheless, most researchers in banking and finance have sought out few of these lessons prior to undertaking their own efforts to assess the benefits and costs of coordinating the formulation of national financial regulatory policies. Consequently, such efforts largely have rediscovered fundamental conclusions that the prior economics literature had already reached. As discussed below, the most important of these is that several key conditions typically must be satisfied before policymakers can feasibly maintain a coordination agreement. Thus, implementing a lasting bargain to coordinate national financial regulatory policies is likely to be a difficult proposition. Indeed, once the scope of the problem that national financial supervisors confront in their efforts to coordinate their policies is fully recognized, the biggest surprise may be that 
it has taken so long for the Basel framework to show signs of stress.

In contrast to most (but not all, as discussed below) of the banking and finance literature on international policy coordination, this policy brief begins by discussing lessons that the broader economics literature has to offer. Section 2 describes the most basic of these lessons. Section 3 then surveys the rediscovery of some of these lessons in a generally belated but growing set of analyses in the banking and finance literature regarding whether international coordination of national financial supervisory policies is desirable and, if so, feasible. Section 4 considers whether fundamental impediments to the coordination of national regulatory policies can be overcome in circumstances in which such coordination is in fact desirable. Section 5 concludes.

\section{Lessons from Economic Analysis of International Policy Coordination}

During the 1980s and 1990s, studies of international monetary policy coordination [for one review, see Daniels and VanHoose (1998)] considered two- or multi-country models in which domestic and foreign monetary policymakers determine their primary instruments of monetary policy (for instance, levels of monetary aggregates, money growth rates, or interest rates). In such theories, the authorities aim to minimize policy losses, which might depend on the inflation rate or deviations of inflation-adjusted national income from a desired level. The value of the loss incurred by one policymaker typically depends both on its own policy instrument choice and on the policy instrument setting of the other policymaker. Hence, the policymakers' instrument choices exert interdependent effects on national losses.

The exact nature of policy interdependence in such monetary policy 
models, of course, depends on presumptions about the structure of the domestic and foreign economies and the nature of the linkages between them. Typically, under a floating exchange rate, increases in the policy instrument choices of the two monetary authorities have opposite effects on the value of each nation's policy loss. If each of the nations' monetary authorities independently pursues noncoordinated policymaking, it determines its policy instrument value taking the other nation's authority's choice as given. Each authority also seeks only to minimize its own policy loss. The resulting noncoordinated policy outcomes fail to take policy interdependence fully into account. In contrast, if the monetary authorities coordinate their choices by jointly determining instrument settings with an aim to minimize a weighted sum of their policy losses, they internalize the policy interdependence that they confront. As a consequence, coordinated choices usually enable both policymakers to attain lower policy losses. A difficulty with attaining this outcome, however, is that after the two monetary authorities reach an agreement to coordinate, each of them almost invariably has an incentive to cheat. Once one of the nation's policymakers has set its instrument at the agreed level, the other typically can set its own instrument at a different value and attain an even lower loss value. This means that maintaining a monetary policy coordination agreement is likely to be challenging.

Another example is in the area of fiscal policy. Suppose that the fiscal policymakers of two taxing jurisdictions-separate political states or nations-confront taxpayers-producers or consumers-who are relatively mobile between the jurisdictions. In this setting, a policy loss experienced by the tax authority in one jurisdiction - which might depend on the deviations of tax collections from an amount of spending to fund and on 
effects on the tax base, such as income or sales/purchases-typically depends positively on its own tax rate but negatively on the tax rate established by the authority in the other jurisdiction. Under noncoordinated policymaking, each fiscal authority selects its tax rate taking the other authority's tax rate as given with an aim to minimize its own policy loss. A consequence is that each authority typically sets a different tax rate than it would if the two authorities mutually coordinated by setting their tax rates simultaneously to minimize a joint policy loss. Again, however, a temptation to cheat typically exists. For instance, if the authorities do agree to coordinate setting higher tax rates, one authority could reduce its tax rate in an effort to induce mobile producers or consumers subject to taxation to shift operations to its jurisdiction, thereby expanding its tax base. As in the case of efforts to coordinate monetary policies, a tax-policy coordination agreement would yield lower losses for policymakers but may be difficult to maintain given the incentives to cheat on the agreement.

At one remove, of course, the underlying tools and objectives of financial regulation are very different from those of, say, policymakers with monetary, fiscal, or international trade responsibilities. A number of essential issues are common to all forms of international policy coordination, however. Thus, certain economic lessons apply to all policymaking environments.

To contemplate the basic implications for financial regulation that are likely to arise from applying the fundamental lessons of the internationalpolicy-coordination literature, consider a very simple setting similar to the more detailed environment studied by Weinberg (2002). Suppose that financial regulatory authorities in two jurisdictions confront clienteles of regulated financial firms that can opt to switch from one jurisdiction to 
another via business reorganizations or perhaps just by obtaining charters from the other authority. The domestic financial regulatory authority's policy instrument is the probability $\pi$ of auditing members of its clientele, and the foreign authority determines its own auditing probability $\pi^{*}$. Conducting an audit entails incurring a cost, but there is an anticipated benefit arising from lower clientele failure costs. Each authority experiences net losses if bank failures are either "too high" relative to a desired level or "too low" in the sense of a low payoff in relation to costs of conducting audits. Whenever each authority raises its own probability of conducting an audit, it reduces its anticipated failure loss. At the same time, however, it experiences a higher audit cost and also gives members of its clientele a greater incentive to contemplate switching to the other authority's jurisdiction.

Figure 1 is drawn under the assumption that the latter effects are predominant, so that a home authority's overall policy loss rises with an increase in its own auditing probability. An increase in the audit probability set by the authority in the other jurisdiction induces regulated financial firms in that jurisdiction to join the home clientele, which reduces the home authority's overall policy loss. Figure 1 also is drawn under the assumption that policy losses are quadratic-that is, involving squared deviations relative to the authority's "bliss point" at which its loss is equal to zero. Thus, the indifference curves-schedules denoted IC that display $\pi-\pi^{*}$ combinations yielding identical losses for each nation's financial regulatory authority-are elliptical. For the domestic authority, point $B$ is the bliss point indicating the single $\pi-\pi^{*}$ combination that eliminates its loss. This bliss point lies on the line denoted $R$, which is the best-response (or reaction) function specifying the domestic authority's optimal setting of $\pi$ in 
response to each possible value of $\pi^{*}$ established by the foreign regulatory authority. Ever-larger ellipses around Point $B$ display sets of $\pi-\pi^{*}$ combinations corresponding to increasing levels of domestic policy losses. Point $B^{*}$, which lies on an analogous best-response function for the foreign authority, is the foreign bliss point that would be the center of another set of ever-larger-circumference ellipses associated with increasing foreign policy losses.

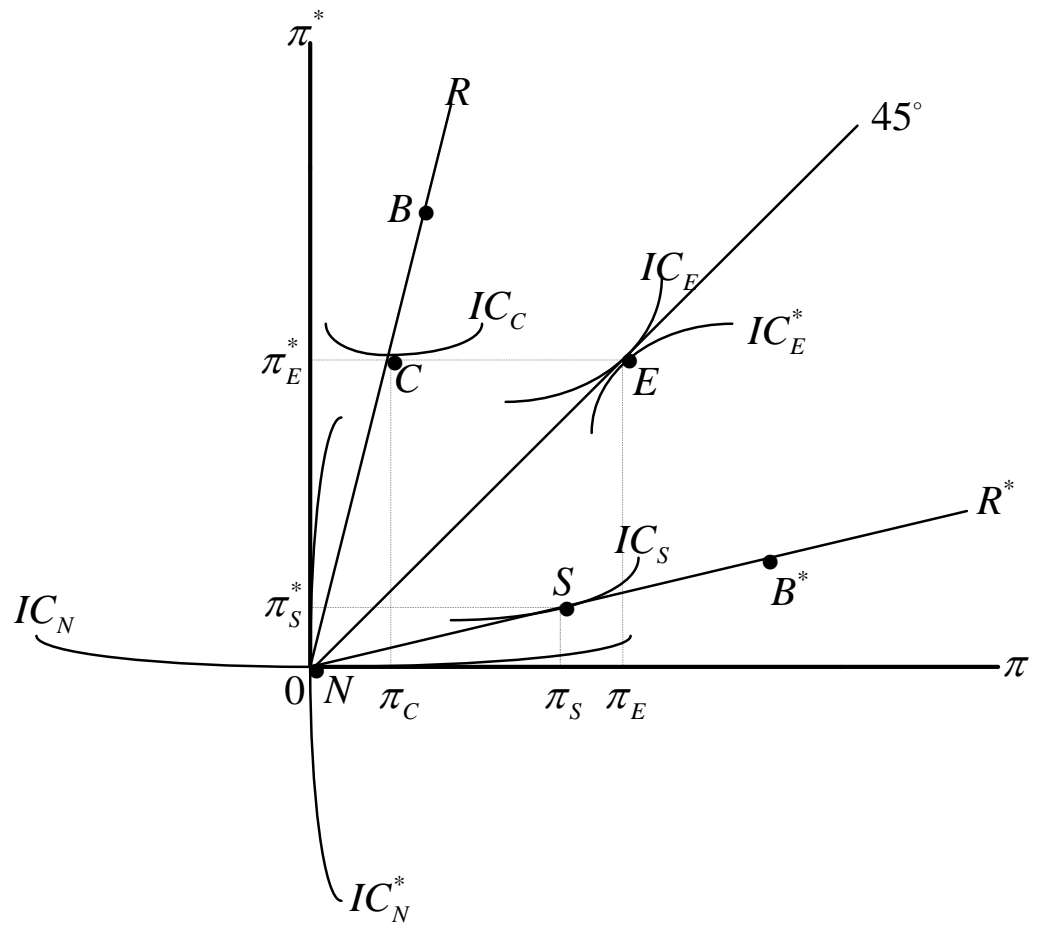

Figure 1: An Illustrative Example of Noncoordinated and Coordinated Financial Regulatory Policies

Point $N$ in Figure 1 displays a situation of noncoordinated financial regulatory policies, in which the domestic authority chooses $\pi$ to minimize only the domestic policy loss taking the foreign authority's choice of $\pi^{*}$ as given, which turns out to be at a point of horizontal tangency with the underside of the domestic indifference ellipse. Additionally at point $N$, the 
foreign regulatory authority chooses $\pi^{*}$ to minimize only the foreign policy loss taking the domestic authority's choice of $\pi$ as given, which turns out to be at a point of vertical tangency with the left-hand side of the foreign indifference ellipse. Although this outcome need not necessarily arise in every possible setting, Figure 1 has been drawn under the simplifying assumption that noncoordinated policymaking yields a regulatory race to the bottom: At point $N$, both authorities opt to set the probability of auditing their clienteles of financial firms at zero, so no audits occur and failure costs are at their maximum. Offsetting these costs for each authority are the facts that it incurs no auditing costs and that it has eliminated any incentive for members of its clientele to switch jurisdictions.

In contrast, point $E$ arises under international financial regulatory coordination, under which the two authorities jointly choose $\pi$ and $\pi^{*}$ to minimize their combined loss. With quadratic policy loss functions, the solution to this policy problem turns out to require the indifference ellipses of the policymakers to be at a point of tangency with equal slopes. Given the assumptions about the nature of policy losses discussed above, coordinated regulatory policies yield higher auditing probabilities at point $C$ than is true of noncoordinated policies at point $N$. The latter policies that yield point $N$ would fail to take into account that if both authorities were to coordinate joint increases in their audit probabilities to the levels at point $E$, they would simultaneously reduce their failure losses while continuing to prevent erosion of their clienteles of regulated financial firms. Figure 1's structure presumes that these loss-reduction gains would be sufficient to more than offset the higher auditing costs incurred, hence reducing both authorities' policy losses. Hence, in the example depicted in Figure 1, coordination "pays" for the two authorities and constitutes an "efficient" 
equilibrium from their points of view.

Point $C$ illustrates the difficulty associated with attaining point $E$. Once the two regulatory authorities agree to set their audit probabilities at levels consistent with point $E$, the domestic authority can gain by reducing its own audit probability in order to reach point $C$ on an indifference ellipse closer to its own bliss point. That is, the domestic authority can gain by cheating on the policy agreement. (Alternatively, but not shown in Figure 1, the foreign authority also stands to gain from cheating and reducing its own audit probability if the domestic authority honors its side of the agreement.) The mutually shared incentive to cheat means that in the absence of a means of ensuring commitment to policy coordination, point $E$ will be difficult to maintain. If either authority yields to the temptation to reduce its national policy loss by cheating, the policymakers eventually will gravitate back toward point $N^{\prime}$ s regulatory race-to-the-bottom outcome. (Point $S$ in Figure 1 is discussed in Section 4 below.)

The difficulty of coordinating policies is analogous to the problem faced by firms that may seek to form cartels establishing collusive pricing and production agreements. Maximizing joint profits requires firms to push their output below noncoordinated competitive levels in order to establish a common, profit-maximizing product price. Once this price is attained, each firm could boost its own revenues and profits by expanding its production. Yielding to this temptation to cheat on the cartel agreement, however, can contribute to a breakdown. In like manner, national authorities often face incentives to renege on international monetary or fiscal policy coordination agreements. Thus, such agreements, like collusive cartels, are naturally tenuous. Cartel agreements tend to be easier to maintain when, among other things, fewer firms inhabit the marketplace, the characteristics of the 
products of participating firms' products are very similar, the firms' production processes and costs are nearly homogeneous, and market demand conditions are relatively stable. Such conditions help to ensure that the gains to coordinating a collusive pricing/production agreement will be substantial and steady for each member, which reduces participants' incentives to cheat. These conditions also simplify the cartel members' task of monitoring each other to assure themselves that all participants are abiding by their collusive pricing and production agreement. Among the authors of banking-and-finance studies, White (1994) appears to have been the only writer who has noted this analogy between the problem faced by cartels and the financial-regulatory-policy coordination problem, but the parallels are obvious.

In the case of monetary policy coordination, Lewis (1989) provides a classic analysis that coordination typically can be maintained only in situations in which gains from coordination are sufficiently high. That is, just as a cartel is easier to maintain when the net gains from coordinating outputs and prices are greatest, monetary authorities will be most likely to abide by policy-coordinating agreements when mutual net gains from such coordination are largest. Otherwise, such agreements naturally have a tendency to break down. Just as participants in a cartel always have incentives to cheat, national policymakers always face temptations to renege on agreements to coordinate policy settings. Lewis shows that in a monetary policymaking context, an international coordination agreement can be most successfully maintained when nations' economies have similar structures, confront primarily common rather than idiosyncratic external shocks, and possess policymakers with homogeneous preferences regarding their ultimate goals. 
As discussed in the following section, recent research is revealing that these same types of considerations matter for assessing both the desirability and feasibility of the coordination of international financial regulatory policies. Hence, banking and financial economists have found themselves rediscovering old lessons. Because these researchers have analyzed models of financial intermediaries and markets, however, in many instances they have identified particular ways in which those lessons apply to supervisory policies of national financial regulators.

\section{Recent Research on International Financial Regulatory Policy Coordination}

A number of studies have sought to evaluate international coordination of financial regulatory policies. One of the most widely cited is that of Dell' Ariccia and Marquez (2006), although earlier independent work by Dalen and Olsen (2003) touches on some of the issues that they consider. In Dell' Ariccia and Marquez's somewhat awkwardly constructed model, there is only one financial institution, or bank, in each country. Timing of

decisions allows for the possibility of imperfectly substitutable loans across countries while retaining the simplicity of a Cournot-style model in which each nation's bank independently determines the quantity that it lends. In the two-country version of the model, each bank first chooses profitmaximizing shares of borrowers from the two countries that it wishes to obtain as loan customers. Once both of the banks make these decisions regarding international loan portfolio allocations, they share credit demand curves from the two countries. After equilibrium quantities of credit are computed and summed, market loan rates for each nation are determined. The loans that the banks extend are risky, but banks can increase the 
probability of success by engaging in costly efforts to monitor borrowers. Although additional monitoring boosts banks' average revenues and increases the stability of their loan portfolios, on net the extra expenses incurred reduce banks' profits.

The regulator in each of the two nations seeks to maximize a weighted average of the profits of its country's bank and of that bank's monitoring effort. A consequence of the imperfectly competitive structure of the international banking market modeled by Dell' Ariccia and Marquez is that if one of the banks cuts back on lending in either country's market, the equilibrium loan rate rises, which pushes up average revenues at both banks. A toughened requirement for costly capital relative to loans at a domestic country's bank induces a lending cutback that simultaneously boosts market loan rates and the bank's average revenues from lending and increases its return from monitoring. In Dell' Ariccia and Marquez's specific model, the unambiguous consequences are increased monitoring and a more stable bank portfolio-outcomes that do not necessarily hold true in all possible banking environments [see, for instance, the review in VanHoose (2007)]. Nevertheless, tighter capital regulation raises the costs for the domestic bank sufficiently to reduce its profits on net. Not surprisingly, therefore, a regulator that places a greater weight on bank profits relative to portfolio stability in its objective function prefers a lower capital requirement.

When the regulators do not coordinate their policymaking, the domestic regulator balances the effects on profits and portfolio stability at its nation's bank. Thus, it ignores the fact that a higher loan rate caused by toughened capital requirements on the domestic bank also generates an increase in average revenues and in the return from monitoring at the 
foreign bank, hence increasing its portfolio stability as well. Consequently, uncoordinated policymaking by the domestic regulator neglects the positive spillover that a domestic capital tightening has on foreign portfolio stability - and vice versa for noncoordinated policymaking on the part of the foreign regulator. [Sinn (2001) reached a similar conclusion in an earlier study.] Dell' Ariccia and Marquez proceed to show that, as a consequence in the context of their model, regulators with the same degrees of relative weighting on bank profits and portfolio stability preferences will choose lower capital requirements than would be chosen if the two regulators instead worked together to coordinate their choices. This conclusion is analogous to the regulatory race-to-the-bottom result under noncoordinated policies obtained in the diagrammatic analysis provided in Section 2, with capital requirements replacing audit probabilities as instruments of regulatory policy.

A related conclusion is that inducing two regulators with identical preferences to agree to coordinated regulation requires the commonly applied capital standard to be set higher than the regulators would have established independently. Tougher capital requirements are necessary because they assure mutual internalization of the positive spillover effects that capital regulation has on portfolio stability in the Dell' Ariccia-Marquez framework.

Dell' Ariccia and Marquez use their model to explore two other issues. The first issue is differences in regulator preferences. They show that as such differences widen, the likelihood of reaching an agreement on policy coordination diminishes. Indeed, beyond a critical preferencedifferential threshold, no agreement is feasible. This conclusion is analogous to that obtained by Lewis (1989) and noted in Section 2. 
Another issue that Dell' Ariccia and Marquez contemplate is how expansion of the theory to multiple countries affects incentives for national regulators to participate in a policy-coordination agreement. A key conclusion that Dell' Ariccia and Marquez reach on this issue is that even if regulators have identical preferences, a subset of regulators will prefer to remain outside a policy-coordinating group. Formation of such a group yields benefits to regulators in countries both within and without, which those on the external margin regarding joining the group must balance against lost bank profits. For some regulators beyond that margin, the reduction in profits can be too substantial in relation to the already freely obtained stability benefits from the coordinating group to justify joining it.

Dell' Ariccia and Marquez's analysis has influenced the work of several other authors. In a framework that deemphasizes cross-border competition among financial institutions but highlights the potential role of liquidity-market externalities, Bengui (2012) reaches the judgment that international policy coordination is unambiguously beneficial to address such externalities. Kara (2013) reaches an analogous conclusion in the case of fire-sale-related externalities. The analyses of both Bengui and Kara presume identical economies and regulator preferences, so their procoordination conclusions are not surprising in light of the discussion in Section 2 above.

Eldridge et al. (2012) also assume homogeneous preferences for national regulators but generalize the Dell' Ariccia-Marquez model by allowing for country size to vary. Eldridge et al. argue that regulators in small countries know that the reactions of their client institutions to supervisory rules will have meager effects on global interest rates and hence are more likely to opt for lax supervision to benefit their domestic clients. 
Hence, their conclusion is that regulators in small nations have greater incentives to deviate from financial-supervisory coordination agreements.

In contrast to Dell' Arricia and Marquez, Morrison and White (2009) examine a setting in which there is no international competition among banking systems. Regulators in separate locales can provide operating licenses to either domestic- or foreign-based banks, however. Consequently, in Morrison and White's model, bank capital (or, as they note in a footnote, alternatively the labor of managers with differing capabilities) is mobile across borders while cross-border trade in banking services does not take place.

Morrison and White examine a trade-off that arises when banking systems in different nations establish a regulatory level playing field -in their model, a common framework for capital regulation-across regulatory jurisdictions. On one hand, a level playing field prevents an international policy spillover in the form of a "cherry-picking externality" that can arise when jurisdictions are differentially supervised. In the latter setting, banks gain-in the form of reputational benefits and looser capital requirements that lead to lower funding costs - from opting to apply for charters to operate in jurisdictions with the best reputations for high-quality regulatory monitoring. This fact enables regulators possessing the best reputations to grant charters to the strongest banks, leaving weaker banks to be supervised by regulators in other jurisdictions. On the other hand, nations can eliminate this cherry-picking spillover via establishment of a level playing field in which the common regulation imposed on banks in all jurisdictions corresponds to the requirement that the weakest regulator would implement. Such a common capital-regulation framework, however, creates regulatory inefficiencies in countries with the highest-quality regulators. 
Morrison and White consider two types of multinational banking (which in their model amounts to "multiple-chartering") arrangements. In the first setting, which they suggest applies most naturally to a short-run situation, banks' initial applications for charters must be to their homecountry regulators. After receiving their initial home-country charters, the banks can then apply for and obtain charters in other jurisdictions. Of course, under this arrangement, no cherry-picking externalities can take place when a bank first receives a charter. Nevertheless, because multinational banks by definition must qualify for charters from regulators with reputations exceeding the lowest quality, regulators can subject them to less stringent supervision than single-jurisdiction banks. The existence of such multinational banks thereby tends to reduce the inefficiencies that regulatory coordination can create.

Under a second, long-run arrangement, banks can apply for charters from multiple regulators in any order they wish. Cherry-picking externalities create a trade-off in the presence of single-jurisdiction banks, which strengthens the case for a level playing field, particularly in the presence of multinational banks. Morrison and White find that level playing fields emerge as a less damaging long-run policy approach than other alternative policy approaches. Indeed, allowing multinational banking is unambiguously welfare improving in their framework. Thus, their argument suggests that permitting multinational banking and long-run adoption - presumably via international policy coordination - of level playing fields are the least costly approaches for regulators to pursue. Clearly, the conclusion about the desirability of international financial policy coordination depends crucially on the extent to which nations' regulators face symmetric policy incentives. Beck et al. (2013) 
evaluate this issue. The authors initially set up a simple closed-economy framework in which a regulator supervises banks with purely domestic operations with an exogenous probability of failure equal to $1-\lambda$. Beck et al. suppose that the regulator will intervene and liquidate a bank offering a one-unit payoff in the event of failure when the known payoff exceeds the expected return from allowing the bank to continue operating, or

$$
\lambda R-(1-\lambda) c<1
$$

where $R>1$ is the gross return if the bank does not fail and $c$ is an exogenous cost incurred if the bank fails. Hence the regulator will intervene when the probability of success is less than the critical value,

$$
\tilde{\lambda}=\frac{1+c}{R+c}
$$

which naturally increases (implying intervention is more likely) when the gross return to success, $R$, is smaller and the failure cost, $c$, is larger.

Next, Beck et al. contemplate a setting with cross-border banking. They interpret $\tilde{\lambda}$ as the efficient threshold value of intervention-one in which the regulator makes its decision without reference to the location of banks' shareholders, depositors, and borrowers. To explore a setting in which the domestic regulator is interested only in domestic gains and costs, Beck et al. suppose that the one-unit certain payoff if the bank is closed is now split between domestic residents and residents of other nations. Domestic residents receive a share equal to $\left(1-\beta_{D}\right) d+\left(1-\beta_{E}\right)(1-d)$, where $d$ is the share of the payoff going to bank depositors, $\beta_{D}$ is the foreign share of deposits, and $\beta_{E}$ is the foreign share of bank equity. The expected return 
from allowing the bank facing the exogenous failure probability $1-\lambda$ to continue to operate is given by the lengthy expression $\lambda\left(1-\beta_{E}\right)(R-d)+\lambda\left(1-\beta_{D}\right) d-(1-\lambda)\left(1-\beta_{A}\right) c$, where the first (positive) term is the expected return received by domestic holders of the bank's equity if the bank succeeds, the second (positive) term is the expected return received by domestic depositors, and the third (negative) term is the expected domestic cost in the event of bank failure, where $\beta_{A}$ is the share of assets financed by the bank relating to foreign projects. Thus, in the presence of cross-border banking the domestic regulator will intervene and close the bank when

$$
\lambda\left(1-\beta_{E}\right)(R-d)+\lambda\left(1-\beta_{D}\right) d-(1-\lambda)\left(1-\beta_{A}\right) c<\left(1-\beta_{D}\right) d+\left(1-\beta_{E}\right)(1-d),
$$

which yields a critical value for the success probability below which the regulator now will intervene equal to

$$
\hat{\lambda}=\frac{\left(1-\beta_{E}\right)(1-d)+\left(1-\beta_{D}\right) d+\left(1-\beta_{A}\right) c}{\left(1-\beta_{E}\right)(R-d)+\left(1-\beta_{D}\right) d+\left(1-\beta_{A}\right) c}
$$

the value of which approaches $\tilde{\lambda}$ as $\beta_{D}, \beta_{E}$, and $\beta_{A}$ all approach unity. Analysis of this ratio indicates that it is larger (so that intervention is more likely) when the foreign-held share of equity in the bank is larger and the foreign-held shares of deposits issued by the bank and assets held by the bank are smaller. On one hand, a larger share of foreign stakeholders in domestic banks leads to a greater misalignment of interests of the regulator with the interests of shareholders, which makes intervention by the domestic regulator more likely. On the other hand, a smaller share of deposits held by foreign residents or a smaller share of credit granted to 
foreign residents imply that the burden of failure will be felt more by domestic residents and makes immediate intervention more likely.

Beck et al. show that these qualitative effects also will hold true as long as the regulator places nonnegative weights on the returns of each of the stakeholders, in situations in which banks exert effort to influence the probability of success, and regulators engage in bailouts rather than bank liquidations. They also examine European and U.S. regulatoryinterventions and bank balance sheet data and find evidence broadly supportive of the predictions forthcoming from their analysis.

The emphasis that Beck et al. place on their results is the potential for inefficient supervision of European banks engaged in cross-border operations. Their analysis has another implication, however. Consider a foreign country in which the gross return on assets, external cost of failure, and other parameters are denoted with asterisks $-R^{*}, c^{*}$, and so on-and in which the numerical values of these foreign parameters all differ at least slightly from those for the domestic nation. The consequence would be that neither the implied value of the efficient foreign success probability threshold for foreign regulatory intervention, $\tilde{\lambda}^{*}$, nor that of the inefficient, foreign-centric threshold, $\hat{\lambda}^{*}$, would typically correspond to those for the domestic nation, given by $\tilde{\lambda}$ and $\hat{\lambda}$, respectively, above. Whether or not the domestic or foreign regulators were interested in pursuing efficient policies as defined by Beck et al., these authorities would exhibit different preferences, ceteris paribus, regarding points at which to intervene and liquidate (or bail out) banks. Hence, reaching agreement on coordinating supervisory rules and actions could well prove to be a problematic undertaking. Kopecky and VanHoose (2012) reach an analogous conclusion regarding any supranational establishment of capital requirements aimed at 
inducing socially optimal monitoring of loan quality by banks.

Beck et al. suggest that a possible response to the problem of reaching a multilateral agreement might be for nations to entrust financial regulation to a supranational institution. After all, as D'Hulster (2011) discusses, if parties are convinced that full coordination of national policies is desirable, the natural conclusion is to impose some sort of centralized rules aimed at eliminating adverse information-sharing problems owing to bureaucratic conflicts of interest. Problems relating to information exchange among supervisory authorities is the key focus of a separate study by Holthausen and Ronde (2004), who indeed conclude that centralization of the supervisory process within a supranational authority can yield higherwelfare bank-closure policies.

Of course, the key real-world supranational institution directly involved in bringing together national financial supervisors has been the Bank for International Settlements (BIS). The primary roles of the BIS, however, have been to serve as a facilitator of cooperative efforts in information sharing and the international coordination efforts that have produced the three Basel agreements. The BIS possesses no supranational authority to impose or enforce such agreements. Such efforts still must be coordinated and enforced by the individual national financial supervisory agencies.

Acharya (2003) provides one of the more interesting studies aimed at evaluating practical issues likely to impede financial-supervisorycoordination efforts. Acharya sets up a model in which identical banks within a nation make either "safe" or "risky" investments financed by deposits that all pay the same promised rate of interest. Equity capital acts as a buffer by reducing the threshold point of default, which results in a 
bailout ("forbearance") with probability $p$. Banks confront countervailing incentives: (1) On one hand, banks have a risk-avoidance incentive because greater risky investment raises the likelihood of losing their charter values;

(2) on the other hand, banks have an incentive to undertake risky investments to maximize the value of their option to default and be bailed out with probability $p$. Thus, if the regulator raises $p$, the bank engages in more risky investments; the likelihood of bank default and hence the probability of bailouts occurring also increase with a rise in $p$.

The bank's optimal capital choice trades off the reduction in likelihood of failure resulting from increased capital against the associated dilution cost of capital. Greater forbearance already buffers the bank against the loss of charter value, so banks react to increased forbearance by preferring less capital. From banks' point of view, therefore, greater forbearance and the privately optimal capital level are strategic substitutes.

A bank regulator determines a minimum required capital threshold to maximize the expected continuation value of all bank claims given the bank's privately undertaken investment allocation decision, subject to incentive-compatibility and participation (charter value must be sufficiently high) constraints. The regulator recognizes that greater forbearance increases the incentive for a bank to allocate more assets to risky investments. The regulator thereby would respond by raising the minimum required capital threshold. Consequently, from the regulator's perspective, the optimal minimal capital requirement and regulatory forbearance are strategic complements.

The essential logic of Acharya's model can be understood by referring to Figure 2. The downward slope of the schedule given by $B B$, which is assumed to be a straight line solely for the sake of simplicity, 
reflects the strategic substitutability of forbearance and the level of capital from a domestic nation's banks' perspective. The upward slope of the $R R$ schedule, also assumed linear as a simplification, is consistent with the strategic complementary of forbearance and capital from the point of view of the nation's regulator. The crossing point of the $B B$ and $R R$ schedules depicts a situation in which both banks and the regulator in that nation attain optimal outcomes at the same degree of forbearance, $p$, and level of bank capital, $K$.

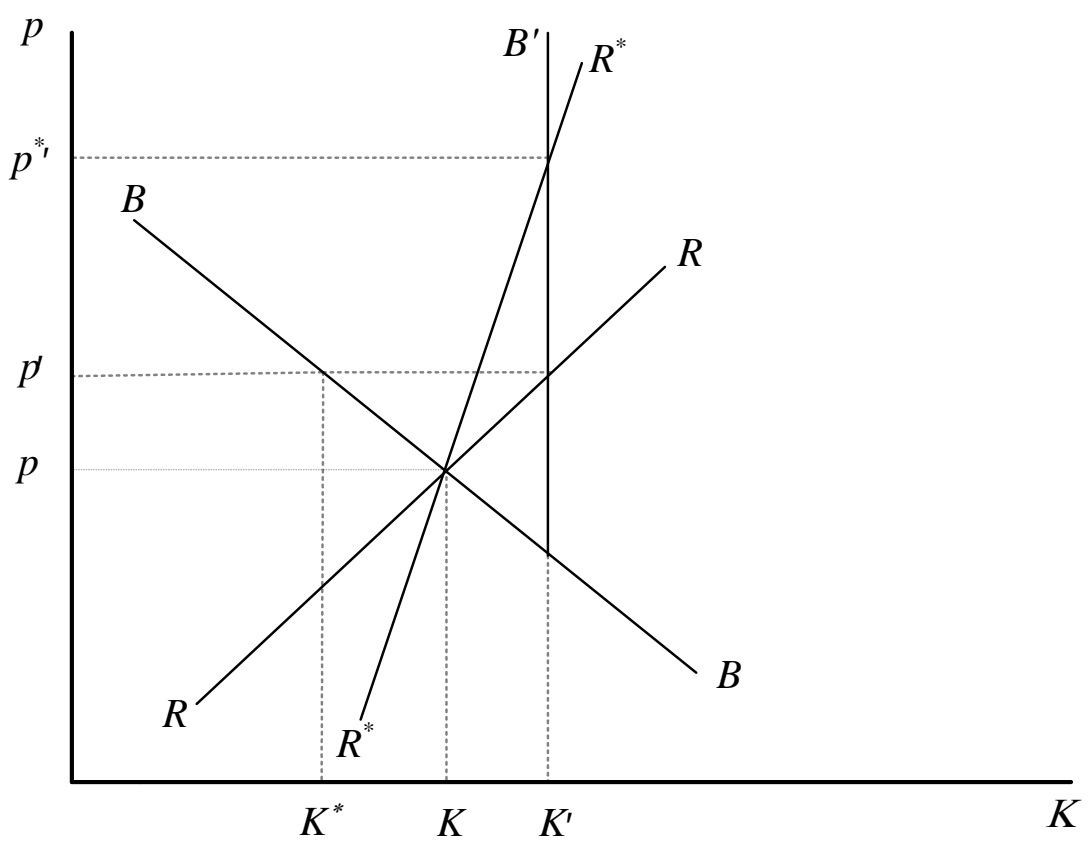

Figure 2: A Diagrammatic Representation of Acharya's Model

The schedule denoted $R^{*} R^{*}$ in Figure 2 applies to a foreign country's regulator. In turn, the foreign regulator is assumed to face a banking system containing institutions identical to those in the domestic nation, so that the $B B$ schedule is applicable for the foreign country. At the crossing point of the $B B$ and $R^{*} R^{*}$ schedules, the banks and regulator in the foreign country initially achieve the same forbearance-capital combination as in the 
domestic nation. The foreign regulator, however, has preferences exhibiting a greater responsiveness of the degree of forbearance to a given change in the level of bank capital.

Now suppose that the two regulators agree to the same, binding minimal capital standard $K^{\prime}$, in which case the kinked schedule $B^{\prime} B$ applies for both banking systems. The consequences, as determined by reference to the $R R$ and $R^{*} R^{*}$ schedules, are increases in the optimal degrees of forbearance chosen by both regulators. In light of the foreign regulator's greater forbearance sensitivity, it opts for a higher degree of forbearance than does the domestic nation's regulator.

Acharya assumes that the banking markets of the two countries are integrated, so banks, borrowers, and depositors can engage in unhindered cross-border arbitrage. The greater degree of forbearance on the part of the foreign regulator enables foreign banks to opt for a larger share of risky investments. The result is a spillover effect operating through cross-border competition that reduces profit margins for domestic banks. To prevent an exit of domestic institutions from the industry - that is, to ensure satisfaction of the participation constraint that it faces-the domestic regulator ultimately will be pressured to raise its own degree of forbearance. Hence, a race to the bottom in regulatory standards eventually must occur, unless the domestic regulator is willing to abandon the participation constraint and observe an evaporation of the domestic banking system. Acharya's analysis demonstrates that this basic conclusion holds for more complicated differences in regulatory preferences than the case depicted in Figure 2, such as when the initial crossing points of the $R R$ and $R^{*} R^{*}$ schedules along the $B B$ schedule differ. As long as the foreign regulator has a greater willingness to forbear, analogous pressures will be placed on the domestic banking system 
and regulator whenever the same minimum capital standard binds both nations' banks.

Naturally, Acharya's analysis reveals more scope for ambiguities to arise when cross-country differences in the structures of the countries' banking systems exist. In the presence of such heterogeneities, the slopes and locations of the nations' $B B$ schedules diverge. In Figure 2, for instance, the foreign version of the $B B$ schedule might be more shallowly or steeply sloped and be shifted in relation to the $B B$ schedule. Allowing for nonidentical regulator preferences and hence different shapes and positions of $R R$ and $R^{*} R^{*}$ would result in a host of varying configurations of pre- and post-capital-requirement outcomes for the two countries. Nevertheless, Acharya shows that pressures for a regulatory race to the bottom will exist in a wide range of such configurations.

Acharya offers two possible policy responses to prevent adverse international spillover effects across bank regulatory regimes. The first of these is full international coordination of all aspects of bank regulationthat is, engaging in cooperative determination of all regulatory instruments, taking into account jointly any existing cross-country heterogeneities, and aiming for mutual attainment of regulatory objectives. The other policy option is host-country-centered regulation, under which any banks seeking to operate within a host nation's borders would have to satisfy that regulator's requirements. In effect, the host country's regulator would grant charters to operate within its borders only to those institutions that agreed to subject themselves to the host regulator's supervision. 


\section{Can Impediments to International Financial Regulatory Policy Coordination Be Overcome?}

Acharya's contrasting policy recommendations suggest that regulators with differing preferences or facing asymmetric national financial environments could face a fundamental tension. On one hand, his conclusions indicate that if policy coordination is feasible, then such coordination promotes financial stability when financial institutions engage in cross-border competition under a coordinated system of transnational supervisory rules. On the other hand, if coordination is not feasible, his results imply that nations can achieve financial stability objectives only if their regulators abandon efforts to maintain open international competition on a playing field characterized by coordinated regulatory policies.

The idea that international stability, openness, and policy objectives can prove to be mutually incompatible in practice is not new. International monetary economists have identified a "trilemma" arising from an inability to achieve simultaneous goals of a fixed exchange rate, mobile financial capital, and independent national monetary policies. Some financial economists have argued that an analogous financial trilemma exists. This financial trilemma is an alleged impossibility of simultaneously attaining objectives of national financial stability, international financial integration, and independently formulated national financial regulatory policies. That is, under a financial trilemma, a nation can attain any pair of these goals: financial stability and international integration, financial stability and independently pursued financial policy making, or international integration and independent financial policies. A nation cannot, however, achieve all three objectives.

Schoenmaker (2011) provides a simple model motivating the concept 
of a financial trilemma, in which authorities in different (presumed national) jurisdictions contribute funds to address the failure of a bank via a "refunding." Such action yields both a benefit, $B$, and involves net cost, $C$. The benefit of such action, however, is distributed fractionally across countries, whose national authorities also contribute fractional amounts of the required failure refundings. Greater international integration spreads the benefits more thinly across countries, which reduces the incentive for national authorities to contribute and thereby reduces financial stability. Moving to a system of coordinated refundings, allows for financial stability but removes the potential for independent financial policy choices. Reduced integration tends to centralize benefits, which increases national authorities' incentives to provide stabilizing refundings but naturally entails less financial integration. Hence a financial trilemma follows naturally in Schoenmaker's framework.

Schoenmaker applies his analysis to European banking and financial regulation. He notes that among the top 60 world banks, those based in the United States and Asia predominantly operate within their home spheres. This limited international integration of U.S. and Asian banking, he suggests, naturally induces national regulators to make a choice within the financial trilemma in favor of a pairing of independent national policies and national financial stability. Schoenmaker argues that the nearly 50-50 split of European banks' operations between home and international markets creates a "trilemma dilemma" for European policymakers. [Related workSchoenmaker and Oosterloo (2005) - provides more detailed evidence consistent with the argument.] Schoenmaker concludes that if European authorities desire national financial stability, then they must choose between either a pairing of international financial integration and European-level 
regulatory policy coordination or non-European-integrated banking integration and independently pursued national financial regulation.

Note that Acharya's policy prescriptions accord with the basic implications of the financial trilemma. In order to effectively promote financial stability (as defined within his specific theoretical framework) while maintaining a level playing field for international financial competition, Acharya concludes that international policy coordination is required. Independent national policies are incompatible with attaining the first two objectives. But if policy coordination is infeasible, so that national financial regulatory policies are conducted independently, then the financial stability goal can be attained only if the idea of integrated financial markets is abandoned.

The logic of the trilemma appears to imply that commitment to financial stability yields a stark either-or choice between a requirement to coordinate international regulatory policies and an objective of achieving international financial integration. Gaspar and Schinasi (2010), which among all the authors cited in this paper are the only ones to anchor their analysis within the broader economics literature on international policy coordination, offer an argument to the contrary.

The essential elements of Gaspar and Schinasi's argument can be assessed within the context of Figure 1 above. They note that an efficient combination of coordinated financial regulatory policies, point $E$ in the figure, should be readily attainable in the absence of Coasean (1960) transaction costs. In the event that such costs exist, for instance, because of heterogeneities in regulators' preferences or differences in the sizes or structures of their economies and financial markets, the feasibility for bargaining among national supervisors to yield the efficient outcome $E$ 
becomes more limited. They argue, however, that this fact does not necessarily rule out the feasibility of policy outcomes that are more desirable than point $N$, the outcome that emerges when there is no policy coordination whatsoever.

Generally speaking, any policy bargain in the setting considered in Figure 1 that moves both nations' financial policymakers' choices to the upper right from point $\mathrm{N}$-that is, in the direction of a range of points roughly between $B$ and $B^{*}$-will result in gains for both countries' regulators. Suppose, for instance, that the foreign financial regulator is aware of domestic political pressures that weigh on the domestic regulator-a source of transaction costs that ultimately would prevent the two parties from being able to maintain a long-term coordination bargain. The foreign supervisor might still be willing to engage in a transaction-costconstrained bargain that nonetheless makes itself better off than settling for a noncoordinated race to the bottom at point $N$. One bargain that conceivably might yield such an outcome would be for the foreign regulator to offer to allow the domestic regulator to act as the "first mover" or "Stackelberg leader." Under this bargain, the domestic financial supervisor would be permitted to establish its own preferred examination probability, taking into account how the foreign regulator will respond. In Figure 1, this arrangement would yield point $S$, at which the domestic regulator's indifference curve is tangent to the foreign supervisor's reaction or bestresponse function, which the domestic supervisor regards as a constraint. Thus, the domestic regulator is permitted to establish an examination probability $\pi_{s}$, which is lower than the efficient, fully coordinated policy setting $\pi_{E}$. Yet the policy setting $\pi_{S}$ provides the domestic regulator with "political cover" that may enable it to implement the bargain successfully. 
The foreign supervisor, which would act as a "Stackelberg follower," then optimally responds with a policy setting $\pi_{S}^{*}$ below the efficient level $\pi_{E}^{*}$. Allowing the domestic regulator to act as a leader yields an outcome at point $S$ that is less preferable to the foreign supervisor than the most efficient, fully coordinated outcome at $E$. Nevertheless, point $S$ is more preferable to the foreign supervisor than the race to the bottom outcome at point $N$.

Gaspar and Schinasi survey key economic arguments advancing the idea that bargains with outcomes that are strictly superior, such as point $S$ in Figure 1, to a purely noncoordinated equilibrium, such as point $N$, can be maintained by parties, such as domestic and foreign financial supervisors. They point out that these arguments indicate that many such bargains that are preferable to the noncoordinated outcome can be feasibly implemented, even if they are inferior to the fully efficient, coordinated outcome. This conclusion arises when the static, one-shot interaction among two parties such as those in Figure 1 is replaced with repeated interactions. When the two parties interact repeatedly, a fundamental condition for feasibility of bargains such as the possibility described above is that the parties must be sufficiently "patient." That is, they must place sufficiently heavy weight on future outcomes relative to current outcomes.

The first-mover assignment bargain is an interesting potentially feasible outcome because when interactions are repeated, the Stackelbergstyle leader-follower structure theoretically can perpetuate itself. Suppose that in Figure 1, once the two supervisors establish an agreement for the domestic regulator to act as the leader, the domestic authority cheats by setting a lower examination probability than $\pi_{s}$. As part of the bargain with the domestic regulator, the foreign supervisor can make clear that in 
response to such an event, in the following and all subsequent periods, it will revert to the noncooperative policy setting $\pi_{N}^{*}=0$. As long as the domestic regulator places sufficient weight on attaining the point $S$ outcomes in these future periods-which from its perspective are more desirable than point $N$ outcomes in any given period-the domestic regulator will choose not to cheat by moving from point $S$ toward point $C$.

In principle, an analogous repeated-interactions (to economists, "dynamic-game-theoretic") argument could be applied to a bargain to fully coordinate policy settings at point $E$. After all, if the domestic regulator cheats after agreeing to coordinate at point $E$, it experiences a one-time gain in welfare at point $C$. But if the bargain entails the foreign supervisor reverting to $\pi_{N}^{*}=0$ for all remaining periods, then all future gains from operating at point $E$ instead of point $N$ will evaporate. Once again, if the domestic regulator cares enough about these future benefits from full coordination, point $E$ can be maintained. Indeed, this type of repeatedinteraction approach to analyzing coordination has been used for many years and now serves as the basis for many theories of collusive cartel behavior utilized by economists who study antitrust issues [see, for instance, Tirole (1989), Vives (2001), and Whinston (2006)].

Nevertheless, the net benefit, relative to bargaining costs to the nations for a bargain that maintains point $S$ over time could turn out to be greater than the net benefit realized from achieving point $C$. Hence, maintaining a bargain to engage in full coordination of financial regulatory policymaking could be more difficult than perpetuating alternative bargains that are less efficient but nonetheless preferable to no bargain whatsoever. There is indeed a range of potential bargains that the two supervisors could, in theory, adopt that would make them better off than allowing a 
noncoordinated regulatory race to the bottom.

As Gaspar and Schinasi note, however, "game theory has low predictive power," in the sense that "any socially feasible allocation that is individually rational can be obtained as an equilibrium." Where does this "low-predictive-power," dynamic-game-theoretic analysis leave the trilemma argument and, more generally, the feasibility of obtaining gains from international financial regulatory policy coordination? Regarding the trilemma issue, taking into account bargaining possibilities holds out more hope for dodging the unequivocal trilemma result. Even if transaction costs limit the scope for striking a bargain to engage fully in policy coordination that yields the most efficient possible outcome, more limited bargains that yield gains to participating regulators may still be feasible.

Concerning the more general gains-from-coordination issue, extending the static, single-shot-game-theoretic analysis utilized in Figure 1 to a repeated-game setting continues to yield ambiguity. Allowing for repeated interactions adds to the standard set of requirements for coordination to pay off that banking and finance scholars have rediscovered, such as homogeneous policymaker preferences, a relatively small number of participants in the coordination agreement, monitoring and enforcement, and similar economic structures. Along with the importance of policymaker patience, Gaspar and Schinasi add the applicable amount of time (number of repeated periods), degree of foresight and predictability of evolution of the policy environment, and transaction and bargaining costs. Accounting for dynamic-game-theoretic aspects of the financial policy coordination problem confronted by national regulators does not necessarily help or harm the case for coordination. 


\section{International Financial Regulatory Policy Coordination: An}

\section{Assessment}

Until very recently, national financial authorities have operated on the implicit presumption that their mutual interests are served by coordinating key regulatory policies, such as the setting of required capital ratios or the establishment of level playing fields for general supervisory rules. Operating on this presumption, these authorities have utilized the BIS to facilitate the establishment of the cooperative Basel agreements that have established a common framework for nations to regulate their financial sectors.

As noted in the introduction, significant recent divergences in regulatory actions and rule-making stances by various national supervisors have taken many financial authorities and economists by surprise. Nevertheless, the initial enthusiasm for international policy coordination in the financial realm followed by a more skeptical assessment of its merits and feasibility echoes analogous experiences in the areas of monetary, fiscal, and trade policymaking. A number of years ago, policymakers and economists operating within these domains likewise had expressed initial enthusiasm that policy coordination could yield significant gains. This eagerness, however, ultimately gave way to a much more tempered enthusiasm as economists identified a wide range of impediments to achieving such gains - and as real-world policymakers acted in their own interests instead of coordinating their efforts.

A number of researchers in banking and finance recently have rediscovered both that fully coordinated policies can potentially offer gains and that achieving and maintaining coordinated policies in pursuit of these gains can be problematic. There is general agreement among researchers 
that completely coordinated financial regulatory policies are likely to be socially efficient. Difficulties arise, however, when national financial markets exhibit heterogeneities or experience asymmetric events or when supervisory authorities place diverging weights on similar goals or seek different objectives. Furthermore, even in cases in which national supervisory authorities might agree to coordinate their policies, the authorities typically confront incentives to cheat on such agreements.

Financial markets naturally offer different sources of such impediments to successful international policy coordination efforts than the problems confronted in other policy realms. Thus, one of the main accomplishments of the banking and finance literature on policy coordination has been to highlight the nature of such impediments within the domain of financial policymaking.

A fundamental issue that financial supervisory authorities pursuing a paramount goal of stability face is a tension between the objectives relating to international integration and the independence of national policymaking. The financial-trilemma logic that has emerged in recent theoretical work suggests that a goal of internationally linked financial markets can be pursued only if national supervisory authorities can coordinate their regulatory policies. If this logic applies at a practical level, and if impediments to coordination ultimately emerge as insurmountable barriers, then attainment of international financial integration goals could be infeasible. That is, national banking authorities may face greater pressures to wall off their financial systems from international competition. A wave of financial protectionism could emerge.

Taking into account lessons from economic analyses of settings in which policymakers engage in repeated interactions offers some measure of 
hope for softening or even avoiding the financial-trilemma logic. When financial supervisory authorities know that decisions they make today influence future as well as present benefits and costs of coordinating their policies, the scope for developing coordination bargains potentially widens. At the same time, however, evaluating the range of feasible policy coordination bargains available for practical implementation becomes a much more complex undertaking. This ambiguous conclusion about the relative merits and feasibilities of coordinating national policymaking is the point reached years ago by economic research on monetary, fiscal, and trade policies. This point now has also been reached by research on financial regulatory policymaking. It remains to be seen whether economists will develop tools for resolving these complexities so as to make possible the effective pursuit of welfare-enhancing coordination of national financial supervisory policies. 


\section{REFERENCES}

Acharya, Viral, 2003. "Is the international convergence of capital adequacy regulation desirable?" Journal of Finance 58(6), pp. 2745-81.

Beck, Thorsten, Radomir Todorov, and Wolf Wagner, 2013. “Supervising cross-border banks: Theory, evidence, and policy," Economic Policy 28(73), pp. 5-44.

Bengui, Julien, 2012. “Macro-prudential policy coordination and global regulatory spillovers," Unpublished manuscript, University of Montreal, September.

Blackstone, Brian, 2013. “ECB faces resistance on banking union," Wall Street Journal, June 4.

Coase, Ronald, 1960. "The problem of social cost," Journal of Law and Economics 3, pp. 1-45.

Crittenden, Michael, 2013. "Regulators rethink complex rules for banks," Wall Street Journal, August 1.

Dalen, Dag Morten and Trond Olsen, 2003. “Regulatory competition and multi-national banking," CESifo Working Paper No. 971, June.

Daniels, Joseph and David VanHoose, 1998. "Two-country models of monetary and fiscal policy: What have we learned? What more can we learn?" Open Economies Review 9, pp. 263-82. 
Dell' Ariccia, Giovanni and Robert Marquez, 2006. “Competition among regulators and credit market regulation," Journal of Financial Economics 79, pp. 401-30.

D’Hulster, Katia, 2012. “Cross-border banking supervision: Incentive conflicts in supervisory information sharing between home and host supervisors," Journal of Banking Regulation 13(4), pp. 300-19.

The Economist, 2013. "Europe's banking union: Till default do us part," June 8.

Eldridge, Damien, Heajin Ryoo and Axel Wieneke, 2012. “Bank capital regulation with asymmetric countries," Working Paper No. 8, School of Economics, La Trobe University, October.

Gaspar, Vitor and Garry Schinasi, 2010. “Financial stability and policy cooperation," Bank of Portugal Occasional paper 1/2010, July.

Hardy, Daniel and Maria Nieto, 2008. "Cross-border coordination of prudential supervision and deposit guarantees," International Monetary Fund Working Paper No. 08/283, December.

Holthausen, Cornelia and Thomas Rønde, 2004. "Cooperation in international banking supervision," European Central Bank Working Paper No. 316, March. 
Kara, Gazi Ishak, 2013. “Systemic risk, international regulation, and the limits of coordination," Unpublished manuscript, University of North Carolina at Chapel Hill, January 10.

Kopecky, Kenneth and David VanHoose, 2012. “Can capital requirements induce private monitoring that is socially optimal?" Journal of Financial Stability 8, pp. 252-62.

Lewis, Karen, 1989. “On occasional monetary policy coordinations that fix the exchange rate," Journal of International Economics 26, pp. 139-55.

Miller, Sally, 2013. "The Fed takes aim at foreign banks," Wall Street Journal, June 18.

Morrison, Alan and Lucy White, 2009. “Level playing fields in international financial regulation," Journal of Finance 64(3), pp. 1099-1142.

Schoenmaker, Dirk, 2011. “The financial trilemma," Economics Letters 1, pp. 57-59. and Sander Oosterloo, 2005. "Financial supervision in an integrating Europe: Measuring cross-border externalities," International Finance 8(1), pp. 1-27.

Sinn, Hans-Werner, 2001. "Risk taking, limited liability, and the competition of bank regulators," NBER Working Paper No. 8669, December. 
Steinhauser, Gabriele, 2013. "Who suffers when banks fail? It depends," Wall Street Journal, June 19.

Tirole, Jean, 1989. The Theory of Industrial Organization, Cambridge, MA: MIT Press.

VanHoose, David 2007. “Theories of bank behavior under capital regulation," Journal of Banking and Finance 310(12), pp. 3680-97.

Vives, Xavier, 2001. Oligopoly Pricing: Old Ideas and New Tools, Cambridge, MA: MIT Press.

Weinberg, John, 2002. "Competition among bank regulators," Federal Reserve Bank of Richmond Quarterly 88(Fall), pp. 19-36.

Whinston, Michael, 2006. Lectures on Antitrust Economics, Cambridge, MA: MIT Press.

White, Lawrence J., 1994. “On the international harmonization of bank regulation," Oxford Review of Economic Policy 10, pp. 94-105.

Zibel, Alan, 2012. "FDIC's Honig: U.S. should reject Basel Accord," Wall Street Journal, Sept. 14. 